AWEJ for Translation \& Literary Studies, Volume3, Number3. August 2019 DOI: http://dx.doi.org/10.24093/awejtls/vol3no3.3

Pp. $37-50$

\title{
An investigation into the interpreters' challenges in conflict zones: The case of Darfur region in Sudan
}

\author{
Holi Ibrahim Holi Ali \\ Dept. of English Language \& Literature, Rustaq College of Education, Oman \\ Awad Alhassan \\ Department of Languages \& Translation, Dhofar University, Oman \\ Ishaq Burma \\ UNAMID, Nyla, Darfur, Sudan
}

\begin{abstract}
The study is aimed to investigate and shed light on some of the challenges encountered by local interpreters and language assistants working for $\mathrm{UN}$ peace-keeping missions, operating in conflict zones, namely in Darfur region, western Sudan. The study addresses the following research questions: what are the linguistic, social-cultural, mistrust and communication-related barriers that are encountered by interpreters and language assistants in conflict zones, how do they cope with these challenges, and what could be done to train them to handle such challenges and difficulties. The study adopted a qualitative methodology with semi-structured interviews being the main method of data collection. Twenty participants agreed to voluntarily take part in the investigation by allowing face-to-face interviews. Interview data was transcribed, coded and analyzed thematically. The results of data analysis showed that participants faced a range of challenges that negatively affected their job. They reported difficulties understanding and dealing with some social and cultural issues specific to the region. They also reported some serious life-threatening incidents ranging from physical and verbal attacks. For example, interpreters encountered hostilities from their fellow citizens accusing them of siding with enemy parties involved in the conflicts. Additionally, communication barriers were reported by participants as being the most salient challenge they experienced even when they interpreted accurately, as they would still encounter communication breakdowns caused by the inherent differences in the indigenous languages and varieties in addition to some cultural barriers. The paper offers some insights and implications for the conflict zones' interpreters' training and professional development.
\end{abstract}

Keywords: challenges, conflict zones, interpreter training, professional development, Sudan

Cites as: Ali, H. I. H., Alhassan, A.m \& Burma, I. (2019). An investigation into the interpreters' challenges in conflict zones: The case of Darfur region in Sudan. Arab World English Journal for Translation \& Literary Studies, 3 (3) 37-50.

DOI: http://dx.doi.org/10.24093/awejtls/vol3no3.3 